\title{
Lindomberto Ferreira
} Alves $^{1}$

\section{A crítica de arte no entrecruzamento da palavra com a imagem}

The art criticism in the intertwining of the word with the image

La crítica de arte en el entrelazamiento de la palabra con la imagen 


\title{
Resumo
}

Partindo de uma elaboração de caráter geneológica, que recupera os percursos teóricos da crítica de processos criativos, busca-se perscrutar, a partir dos aspectos que atravessam seus procedimentos teórico-críticos, caminhos possíveis aos desafios enfrentados pela crítica de arte ante a intrincada relação obra-processo tensionada pela poética artística contemporânea.

Palavras-chave: Crítica genética; Crítica de processo; Processos criativos; Crítica de processos criativos; Crítica de arte.

\begin{abstract}
Abstract: Starting from an elaboration of a geneological nature, which recovers the theoretical paths of the critique of creative processes, the aim is to investigate, from the aspects that go through their theoretical-critical procedures, possible paths to the challenges faced by art criticism in the face of the intricate work-process relationship tensioned by contemporary artistic poetics.
\end{abstract}

Keywords: Genetic criticism; Process criticism; Creative processes; Creative process critique; Art criticism.

Resumen: Partiendo de una elaboración de carácter genealógico, que recupera los caminos teóricos de la crítica de los procesos creativos, se pretende investigar, desde los aspectos que atraviesan sus procedimientos teórico-críticos, posibles caminos para los desafíos que enfrenta la crítica de arte frente a la intrincada relación trabajo-proceso tensionada por la poética artística contemporánea.

Palabras clave: Crítica genética; Crítica de procesos; Procesos creativos; Crítica de los procesos creativos; Crítica de arte.

\footnotetext{
${ }^{1}$ Artista-educador, pesquisador, crítico e curador independente. Mestrando em Teoria e História da Arte pelo PPGA-UFES (2018/20). Licenciando em Artes Visuais pela UNAR/SP (2020) e Bacharel em Arquitetura e Urbanismo pela UFBA (2013). É membro do grupo de pesquisa "Curadoria e Arte Contemporânea" e integra a equipe da "Plataforma de Curadoria" (DAV-UFES), plataforma virtual focada nos processos de criação em curadoria. Possui textos publicados em livros, catálogos e revistas especializados nos campos da história, teoria e crítica de arte. Suas investigações privilegiam a análise dos processos de criação na arte contemporânea, de modo especial, no estudo de produções cujos processos criativos colocam arte, vida e obra no mesmo plano de contágio. Site: https://lindomberto-ferreira-alves.webnode.com/ E-mail: lindombertofa@gmail.com Currículo lattes: http://lattes.cnpq.br/4752217428368108 Orcid: https://orcid.org/0000-0001-7832-1734
}

ISSN: $2175-2346$ 


\section{Introdução}

Apesar de se tratar de um campo reflexivo relativamente novo - e em pleno estágio de expansão, sobretudo no cenário da produção científica nacional ${ }^{1}$ - o interesse pelo processo de criação artística remonta cerca de meio século de discussões, análises e pesquisas nos mais variados campos epistemológicos. Em sua origem, nos idos da década de 1960, tais esforços convergiram exclusivamente à reconstituição da gênese da obra literária e, portanto, encontravam-se circunscritos no âmbito do acompanhamento teórico-crítico do processo de criação no campo da literatura. Entretanto, com o transcorrer dos anos, vimos delinear-se uma exponencial escalada da importância nos processos criativos, que excederam os limites da criação literária, alcançando outros territórios da criação artística que, não apenas, a literatura - a exemplo das artes visuais.

No que tange o campo das artes, mais especificamente o campo das artes visuais, embora a busca pela compreensão do estatuto poético da obra de arte não se limite à emergência desse escopo de estudo - dado que esta ocupa lugar de destaque ao longo do movimento geral da história da arte - deve-se em grande medida à abordagem da teoria do processo de criação ${ }^{2}$ os avanços em termos de atualização prático-discursiva sobre o olhar investigativo em torno do processo de criação artística e, por extensão, da própria revisão dos pressupostos metodológicos e dos aportes teóricos utilizados pela crítica de arte na atualidade. Trata-se, desde os anos de 1980, de uma postura que ao introduzir na crítica a noção de tempo - posto que "o tempo do trabalho é o grande sintetizador do processo criador" (SALLES, 1998, p. 32) - busca refletir sobre a obra de arte na contemporaneidade, a partir, também, dos múltiplos registros e documentos processuais dos artistas, e não somente a partir do objeto concluído. De acordo com José Cirillo³, ao se acessar o processo de elaboração e fabricação da obra:

\footnotetext{
Passaram a ser investigadas as nuances da criação da obra, buscando revelar novas perspectivas dos fenômenos sensiveis a partir de um compartilhamento com a mente do artista no momento da criação, cujas marcas memoriais encontram-se grafadas nesses arquivos e documentos, muitas vezes condenados ao esquecimento com a finalização da obra (CIRILLO, 2019a, p.12)
}

Nesse sentido, acredito, junto a Nicolas Bourriaud (2011), que tão dignos de atenção crítica quanto as obras de um artista, são seus relatos, seus gestos e seus modos de existência - tantas vezes prescindidos, como sublinha José Cirillo - afinal de contas, é nessa esfera que começa o fazer artístico. Aliás, como o próprio Bourriaud faz questão de ressaltar, "o produto do trabalho (artístico) não pode ser considerado fora das condições de sua produção" (BOURRIAUD, 2011, p. 67). E essa não parece se tratar de uma posição isolada, dado que de acordo com Cecília Almeida Salles (1998, p.104), "em seu processo de apreensão do mundo, o artista estabelece conexões novas e originais, relacionadas a seu grande projeto poético". Em face dos desafios produzidos por esse multifacetado campo de efetuações no qual são agenciados os processos de criação artística, não nos resta dúvidas de que "urge ampliar o sentido 
da crítica, exigindo que ela se aproxime do indeterminado, acompanhando a deriva do trabalho de arte" (BASBAUM, 2001, 25). Assim, partindo de uma elaboração de caráter geneológica, que recupera os percursos teóricos da crítica de processos criativos, busca-se, aqui, perscrutar, a partir dos aspectos que atravessam seus procedimentos teórico-críticos, caminhos possíveis aos desafios enfrentados pela crítica de arte ante a relação obra-processo tensionada pela poética artística contemporânea.

\section{Da crítica genética à crítica de processo}

Oriunda dos estudos literários, a emergência da perspectiva teórica da crítica genética - assim intitulada, em 1979, pelo crítico francês Louis Hay - foi responsável por oferecer aos pesquisadores do campo da literatura todo um horizonte metodológico capaz de compreender e discutir o processo de criação literária por meio dos registros e manuscritos do escritor. Ao deslocar o foco de atenção do texto para o seu processo criativo, a crítica genética visou o que se denominou de prototexto, ou documentos autógrafos, o "conjunto de documentos que precedem o texto (notas de leitura, cópias impressas, rascunhos, provas corrigidas, projetos, cópias passadas a limpo, testemunho da obra)" (REGINA \& SANTOS, 2015, p. 10). Desse modo, sob a égide do conceito de gênese - "que tem fortes resquícios de busca e, portanto, crença na existência de origem" (SALLES, 2017a, p. 47) - os estudos genéticos promoveram um substancial deslocamento de tendência na atividade de análise crítica de textos no campo dos estudos literários, tornando possível ao crítico "conhecer não sobre a legitimidade de uma obra, mas como são desenvolvidas as operações mentais realizadas pelo artista para construí-la, ou seja, a estética do processo" (GOYA, 2009, p. 02). No que concerne aos possíveis desdobramentos tencionados pela premência dos estudos genéticos, Edna Goya (2009) sublinha, ainda, que:

A consequência primeira das investigações no campo genético seria abalar e desmistificar os hábitos da tradição de arte como feitos de gênio, tratando-a como produção sensível, inteligente, portanto como trabalho. A crítica genética veio ainda para enfrentar a descrição da obra enquanto produto pronto, acabado, isolado em si mesmo e, diferentemente de outras linhas teóricas que trabalham a partir de uma abordagem psicanalítica, centrada no autor, opta pelas ações do sujeito enquanto produtor, pelos documentos de processo de elaboração da obra (GOYA, 2009, p. 02).

Entretanto, faz-se importante pontuar que "os inícios reais da crítica genética atual fizeram-se, pois, [...] fora de qualquer ambição teórica e mesmo desconectados de qualquer tradição filológica [...]" (GRÉSILLON, 1991, p. 09). Fruto do acaso e com a experiência empírica, o que estava em jogo no vórtice da origem da crítica genética dizia respeito à urgência em ter que lidar com um novo eixo de questões metodológicas no âmbito do manejo dos documentos autógrafos. Em outras palavras, seu surgimento dá-se em uma conjuntura bem singular: aprender a explorar, classificar e editar uma importante coleção de manuscritos do poeta alemão Heinrich Heine (1797-1856), adquirida em 1966, pela Biblioteca Nacional da França. Ou seja, o que 
em momentos anteriores era tratado tão simplesmente como monumento/patrimônio, a partir desse caso passa ser encarado com objeto de estudo e produção científica, cuja análise - inicialmente via codicologia 4 - dos registros processuais de criação do autor, permitiria a reconstituição dos mecanismos de produção escritural da obra 5 .

Se o caso francês ora mencionado tenha desencadeado, nos anos que se seguiram, um aumento no interesse pela criação literária, não podemos nos esquecer de que foi na Alemanha - por interposição da inquietação de escritores modernos, como Novalis, Goethe e Schlegel, com a gênese textual - onde primeiramente manifestou-se "um desejo dos escritores de entrar no ateliê da escritura" (WILLEMART, 2001, p. 173). Todavia, foram de fato os próprios franceses, na esteira dos caminhos abertos pelos alemães, os responsáveis pela afirmação e consolidação dessa postura analítica também no plano teórico, de modo que fosse "possível a produção de um conhecimento crítico relacionado aos manuscritos" (PINO, 2004, p. 90). A esse respeito, um dos personagens balisares - e por que não dizer central - na formação desse campo de estudos, que, por sua vez, logo veio a se transformar em uma nova disciplina, foi o crítico literário francês Louis Hay.

A experiência de Louis Hay na coordenação da equipe encarregada, em 1966, pela recuperação e manejo dos manuscritos de Heinrich Heine para subsequente publicação, foi além da criação. No intuito de contribuir na compreensão do processo criativo, analisando os documentos que testemunham a gênese dos trabalhos, ele criou, dez anos mais tarde, em 1976, do "Centro de Análise de Manuscritos" - renomeado, menos de uma década depois, para "Instituto de Textos e Manuscritos Modernos" - no intuito de contribuir na compreensão do processo criativo, analisando os documentos que testemunham a gênese dos trabalhos. Tais experiências ainda conduziram o crítico, ainda, à publicação, em 1979, do volume intitulado "Ensaios de Crítica Genética", que de certa forma muniu os, até então, especulativos estudos geneticistas de toda uma reflexão teórica, além de técnica e metodológica, para a análise de seu novo objeto, o manuscrito. Em relação aos efeitos produzidos pelas reflexões do crítico francês em torno do texto e da sua gênese, Silvia La Regina e Adna Evangelista Couto dos Santos (2015) apontam que:

\begin{abstract}
Quando Louis Hay [...] disse "O texto não existe", provocou grandes questionamentos sobre a noção de texto, fomentou a ideia de pensar o texto como uma das etapas da realização de um processo que permanece sempre em transformação, não mais como preconizava o estruturalismo, o texto fechado em si mesmo, com autoridade irrefutável, mas como um leque de possibilidades de produção e de leituras interpretativas (REGINA; SANTOS, 2015, p. 17).
\end{abstract}

Consolidada no cenário da pesquisa literária alemã e francesa - sob o prisma de uma certa especificidade que se define na escolha "[...] da produção sobre o produto,

\footnotetext{
4 Segundo (RODRIGUES, 2016, p. 615), a codicologia é um campo de estudos que visa "fornecer elementos para a análise dessas fontes primárias: os livros manuscritos. Oferecer ferramentas para a interpretação histórica e para a tentativa de compreender as imagens contidas nas páginas, um exercício de leitura desses conjuntos visuais e das particularidades físicas desses livros".

5 Conforme explica Roberto Zular (2002), depois da polêmica do estruturalismo, era impossível voltar à crítica de fontes, ou procurar o "texto original" nos documentos. A solução encontrada foi estudar o processo de criação do texto literário a partir de procedimentos estruturalistas.'
} 
da escritura sobre o escrito, da textualização sobre o texto [...]" (GRÉSILLON, 2007, p. 19) - a crítica genética chega ao Brasil, na década de 1980, mais especificamente em 1985, através da realização do "I Colóquio de Crítica Textual: O Manuscrito Moderno e as Edições", organizado na Universidade de São Paulo, pelo pesquisador francês Philippe Willemart ${ }^{6}$. Além de introduzir a discussão em torno dos estudos geneticistas nos meandros dos departamentos de literatura das universidades brasileiras, o evento também oportunizou, na ocasião, a criação da "Associação dos Pesquisadores dos Manuscritos Literários", bem como da revista científica "Manuscrítica"7 que, desde 1990, configura-se como um dos mais importantes meios de publicização, com projeção nacional e internacional dos estudos genéticos no Brasil. Ainda na década de 1990, Philippe Willemart, fundou na Universidade de São Paulo, junto a outros psquisadores, o "Laboratório do Manuscrito Literário" e o "Núcleo de Apoio à Pesquisa em Crítica Genética" (NAPCG) ${ }^{8}$. O crescimento da pesquisa em crítica genética no Brasil passou assim a congregar, também, os arquivistas, os filólogos, os editores críticos, os bibliotecários dos acervos, os codicologistas, os críticos literários, passando todos estes a fazerem parte do amplo campo de estudos aberto pela gênese das artes (WILLEMART, 2001). No início dos anos 2000, os esforços em penetrar nas tessituras do processo criativo já contavam com outros grupos de pesquisa distribuídos pelo país, sediados na USP, na PUC-SP, na UFES, na UFMG, na UFPB, na UFBA, na PUC-RS e na UFRGS, além da Fundação Casa Rui Barbosa, no Rio de Janeiro.

Tamanha foi a aceitação da perspectiva da crítica genética nos ambientes das instituições acadêmicas que, durante a década de 1990, avolumaram-se publicações ${ }^{9}$ s quais, ao mesmo tempo em que endossavam sua efetivação teórico-metodológica no âmbito da análise da criação literária, despertavam o interesse em "romper a barreira da literatura e ampliar seus limites para além da palavra" (CARDOSO \& SALLES, 2007, p. 44), permitindo, assim, "conhecer alguns procedimentos da criação, em qualquer manifestação artística, a partir desses registros deixados pelos artistas" (Idem, ibidem, p.44). Decerto, uma das figuras responsáveis por delinear a expansão dos estudos genéticos rumo às outras esferas da criação artística foi a pesquisadora brasileira Cecília Almeida Salles. Em 1992, na publicação da primeira edição de seu livro "Crítica Genética: Uma Introdução", a pesquisadora põe uma espécie de lente de aumento sobre essa questão da ampliação ${ }^{10}$ da crítica genética, uma vez que:

6 Radicado no Brasil, Philippe Willemart entrou em contato com a crítica genética em 1982, no Pós-Doutorado, na França, quando lhe foram oferecidos pelo seu orientador os manuscritos de Gustave Flaubert. Adepto do estudo sobre psicanálise e literatura, entendeu que era possível estudar o funcionamento do inconsciente por intermédio do manuscrito.

7 A Manuscrítica - Revista de Crítica Genéticaé umapublicação da Associação dos Pesquisadores em Crítica Genética (APCG) e da Pós-graduação em Estudos Linguísticos, Literários e Tradutológicos em Francês, da Universidade de São Paulo. Desde 1990, publica textos que dialoguem com a crítica genética, disciplina que estuda os processos de criação em diversas áreas, como a literatura, artes plásticas, teatro e cinema, entre outras. Para maiores informações, acessar: $<$ <ttp://www.revistas.fflch.usp.br/manuscritica/index>.

8 Atualmente o NAPCG congrega as equipes da PUC-SP, da Universidade Federal de Espírito Santo e as cinco equipes da USP, duas das quais são do Instituto de Estudos Brasileiros (IEB) e três do departamento de Letras Modernas da Faculdade de Filosofia, Letras e Ciências Humanas.

9 Neste contexto, "foram produzidos muitos artigos, teses, dissertações que se dedicam ao acompanhamento da produção de obras de Daniel Senise, Ignácio de Loyola Brandão, Evandro Carlos Jardim, Regina Silveira, Graciliano Ramos, Carlos V. Fadon, Lucas Bambozzi, Eugène Delacroix, Paul Gauguin, Joan Miró Luis Paulo Baravelli, Roberto Santos, Elizabeth Bishop, Cildo Meireles, Caio Reisewitz, para citarmos somente alguns" (CARDOSO \& SALLES, 2007, p. 46).

10 Essa ampliação deu-se, inicialmente, a partir das contribuições teórico-metodológicas tensionadas na tese de doutoramento "Criação em processo: Ignácio de Loyola Brandão e Não verás país nenhum" (1990), defendida por Cecilia Salles, bem como das investigações desenvolvidas, à época, pelo Centro de Estudos de Crítica Genética (hoje, "Centro de Estudos em Processos de Criação") do Programa de Pós-Graduação em Comunicação e Semiótica Pontifícia Universidade Católica de São Paulo (CECG-PUC/SP). 
Foi assim que nasceram e assim estão sendo desenvolvidas as pesquisas até o momento. No entanto, sabemos ser inevitável a necessidade de ampliar seus limites. Certamente, ouviremos falar, em muito pouco tempo, sobre estudos de manuscritos em artes plásticas, música, teatro, arquitetura ... até manuscritos científicos. Isto oferece novas perspectivas para pesquisas sobre as especificidades e as generalidades dos processos criativos artísticos, para não mencionar a possibilidade de se adentrar o interessante campo de pesquisa dedicado à relação ciência/arte - agora sob a ótica genética (SALLES, 1992, p.106).

Ora, o que até então parecia se tratar de uma hipótese "inscrita na própria definição do seu propósito e de seu objeto de estudo" (CARDOSO \& SALLES, 2007, p. 44), ganhou um espaço concreto de investigação com a fundação, em 1993, do "Centro de Estudos de Crítica Genética", com coordenação de Cecília de Almeida Salles. Sediado no âmbito do Programa de Comunicação e Semiótica da PUC/SP, o grupo de pesquisa reuniu "alunos com formações e interesses bastante diversos, tais como jornalismo, publicidade, artes visuais, arquitetura, artes cênicas, cinema, literatura, design, etc" (SALLES, 2017a, p. 42), interessados na complexa rede dos processos de criação nas artes e nas mídias. Dada a diversidade da natureza dos objetos dos pesquisadores envolvidos no grupo, fez-se necessário, com base na semiótica de Charles S. Pierce, a busca por questões gerais do processo criador. Assim, o acompanhamento teórico-crítico de uma amostra relativamente diversa de processos, em princípio, bastante singulares e heterogêneos, permitiu "a observação de várias características comuns nesses percursos, que viabilizou essa teorização de natureza geral dos processos de criação" (Idem, ibidem, p. 44). A respeito das generalizações sobre o fazer criativo que conduziram à teorização da crítica de processo de criação, a própria Cecília Almeida Salles (2017a) adverte:

Não seriam modelos rígidos e fixos que, normalmente, mais funcionam como fôrmas teóricas que rejeitam aquilo que nelas não cabem. São instrumentos teóricos que permitem a ativação da complexidade do processo. Não guardam verdades absolutas, pretendem, porém, ampliar as possibilidades de discussão sobre o processo criativo (SALLES, 2017a, p.45).

Essa teoria geral do processo de criação artística foi sistematizada, pela primeira vez pela pesquisadora, no volume "Gesto Inacabado: Processo de Criação Artística", publicado em 1998 - que se encontra, hoje, em sua 5a edição. Partindo do pressuposto de que a criação trata-se de um fenômeno em transformação - ancorada no conceito de semiose ${ }^{11}$, oriunda da semiótica pierceana - o livro propõe, portanto, uma leitura da criação como processo sígnico (SALLES, 1998). Entretanto, para que esse argumento ganhasse consistência teórica, alguns ajustes metodológicos e terminológicos se fizeram necessários, como, por exemplo, a adoção do termo documentos de processo no lugar do uso do termo manuscrito, tendo em vista suas

11 É importante sublinhar, aqui, que é o processo de semiose - e não o semiótico - que é privilegiado na sistematização dessa teoria geral do processo de criação artístico, entendendo que o que está em jogo nessa construção é o processo de leitura e assimilação dos documentos autógrafos de uma obra, ao invés da preocupação apenas com a análise dos signos. A análise semiótica, propriamente dita, entra, também, apenas como parte do processo. 
limitações ${ }^{12}$ para lidar com a diversidade das linguagens exploradas pelas mais distintas manifestações artísticas. A respeito desses ajustes e de suas amplitudes de ação, Cecília Almeida Salles (2017a) comenta:

[...] documentos de processo pareceu cumprir esta tarefa, dando destaque à função desempenhada pelos registros - necessidade de reter algumas ideias ou ações - e não à sua materialidade. Assim pode-se falar de documentos sob a forma de cadernos, anotações, diários, assim como ensaios teatrais, copiões, esboços etc., incluindo todo o potencial oferecido pelas mídias digitais. Nesta perspectiva, as novas tecnologias em vez de apontarem para o fim desses documentos, contribuem para o aumento da diversidade e sua ampliação constante. Os registros analógicos e/ou digitais do percurso são feitos na linguagem mais acessível ao artista naquele momento, seja escrita, oral ou visual. Nesse contexto temos, por exemplo, os registros fotográficos e audiovisuais das artes cênicas enfrentando os desafios de documentar processos criativos no teatro, dança e performance. A metodologia, por sua vez, também vem se mostrando em processo de expansão: muitos pesquisadores, especialmente no caso de teatro e cinema, passam a acompanhar processos, gerando outros documentos, sob a forma de anotações, fotografias, registros audiovisuais etc. (SALLES, 2017a, p. 46-47).

Dados os rumos tomados com tais ajustes e, em função das restrições à denominação crítica genética que estes acabaram por impor, o "Centro de Estudos de Crítica Genética" opta por mudar seu nome para "Centro de Estudos em Processos de Criação". Tal escolha não parece ter sido arbitrária, uma vez que o conceito de criação adotado na perspectiva da crítica de processo, diferentemente da perspectiva da crítica genética, entende o processo criador como processo contínuo, ou seja, "ressalta a regressão e progressão infinitas do signo" (Idem, ibidem, p. 48). Dito de outra maneira, a continuidade inerente ao processo de criação de que nos alerta a crítica de processo, significa e implica "a destruição do mito do signo originário e do último absoluto" (Idem, ibidem, p.48). Ainda nesse sentido, outro aspecto central dessa teorização, atrelado a ideia de continuidade, diz respeito a não linearidade e, portanto, ao inacabamento da criação. Ou seja, trata-se de se discutir as obras como fenômeno em transformação, em estado de contínua metamorfose, cujas reflexões desencadeadas após o acontecimento da obra são partes constituintes do processo, colocando, processo de criação, obra e mediação com o mundo exterior em uma complexa rede de interações em contínuo estado de construção - o que nos levaria à estética do inacabado (SALLES, 1998).

\section{A arte contemporânea e a interdependência entre processo e obra}

Não podemos, entretanto, deixar de notar que essa possível teoria crítica de processo, que discute a criação como rede em construção, como instância em pro-

\footnotetext{
12 Se o termo manuscrito no domínio da crítica genética em literatura já não abrangia uma gama de registros que iam para além do escrito à mão (posto que dependendo do escritor os investigadores se deparavam com documentos escritos à máquina, digitados no computador ou em provas de impressão), em outros domínios do fenômeno artístico a utilização do termo se tornava insustentável, dado que em linhas gerais a ideia de registro, a partir desse termo, estava estritamente ligada à linguagem verbal. Pode-se dizer, também, que a noção de documentos, independente de sua materialidade, contêm sempre a ideia de registro (CARDOSO \& SALLES, 2007).
} 
cesso, em estado de transformação, desenvolve-se, não por acaso, no bojo de uma espacial atenção às experimentações contemporâneas - decorrentes da crise das vanguardas históricas, na passagem dos anos de 1960 para os anos 1970, bem como da crise na reflexão estética e na crítica de arte. No campo das artes visuais, essas experimentações não só contribuíram sobremaneira com o "deslocamento das funções instauradoras (a poética do artista) para as funções da sensibilidade receptora (estética)" (PLAZA, 2003, p. 09) - atualizando o próprio conceito de 'aristotélico ${ }^{13}$ via ampliação das possibilidades interpretativas sobre a noção de criação ${ }^{14}$, suscitadas pelos processos criativos engendrados por elas. Como, também, acabaram por exigir a expansão do olhar crítico interessado no trabalho de arte e na criação artística, explorando outros caminhos para além da análise do objeto e/ou dos estudos dos arquivos pessoais dos artistas, sem abandoná-los.

Assim, cabe, aqui, circunscrever, ainda que brevemente, os desdobramentos dessas crises, naquilo que diz aos processos de criação tensionados via experimentações artísticas engendradas entre a segunda metade do século XX e o início do século XXI. Espera-se que essa contextualização forneça alguns subsídios que conduzam à reflexão da teoria de processos criativos como um possível modo de interlocução crítica com o trabalho de arte em face do multifacetado campo de efetuações poéticas que agenciam a criação artística no contemporâneo. Comecemos, portanto, por Marcel Duchamp. Embora o artista francês, por volta de 1913, já tencionasse com seus ready-mades uma crítica ácida aos valores poéticos estéticos e aos cânones consolidados de validação da obra de arte, é anos mais tarde, em 1957, no texto "O ato criador", que o artista sistematiza sua reflexão sobre a criação artística e nela a importância crucial do papel do espectador na atribuição do coeficiente artístico à obra. No texto, o artista sustenta que a criação não é uma ação exclusiva do artista ${ }^{15}$, mas também do espectador, o qual, segundo Duchamp (1975, p. 73), é quem determina "qual o peso da obra de arte na balança estética", tendo em vista que é ele, o espectador, que faz o "contato entre a obra de arte e o mundo exterior, decifrando e interpretando suas qualidades intrínsecas".

Em consonância com a afirmação do ideário moderno de autonomia da arte e a emergência do conceito de obra aberta ${ }^{16}$, o posicionamento de Duchamp - aliado

\footnotetext{
13 Para Arantes (2005, p. 63), "tentando estabelecer os alicerces da definição artística, Aristóteles não se pergunta, como seu mestre Platão, o que a arte imita, mas como ela imita, onde se enraíza o seu termo poiésis. Poiésis em grego significa criação, fabricação, produção: significa produzir que se engendra, uma criação que organiza e instaura uma nova realidade. Para o filósofo grego, a natureza e os seres vivos são fruto do ato "poiético" da inteligência divina, que conduziu a matéria do estado de caos e indeterminação inicial ao estado de realidade. É este ato "poiético" que a arte imita; a ação criativa da natureza - o seu potencial de transformação e de vir-a-ser - já que é através da ação do artista que o mármore pode se transformar, por exemplo, em uma escultura". Note-se, entretanto, que em decorrências das experimentações artísticas da contemporaneidade, o conceito de poiésis, dentro de um entendimento mais amplo, se atualiza na medida em que passa abranger tudo aquilo que é produzido, sem necessariamente se dar como fruto de algum nível de consciência estética.
}

14 Com essas experimentações, institue-se "a noção de que a poética diz respeito à obra em processo, logo, a obra no momento mesmo em que o artista a elabora. A poética, desta maneira, diz respeito ao ofício mais diretamente atrelado ao ato criador, à produção artística em si” (ARAÚJO, 2017, p. 115). Assim, nessa perspectiva, passa-se "entender o ato de criar como uma construção em movimento: um processo dinâmico, na condição de sempre poder vir a ser, não se configurando, portanto, como algo previamente acabado" (TAVARES, 2011, p. 37).

15 Faço, aqui, uma pequena ressalva. Pois, embora haja na perspectiva duchampiana uma implicação em relação ao processo de transvaloração da arte e, consequentemente, um deslocamento da arte da obras, Favaretto (2011, p. 97) adverte que, paradoxalmente o mesmo não acontece com a figura do artista, "exatamente porque sua aderência à concepção de criação, ou de invenção, é cada vez mais forte - como aquela que resulta do ato duchampiano. [...] Enquanto nas vanguardas 'as noções correlatas de obra e de autor perdiam sua consistência, a de artista conservava a sua e talvez mesmo a reforçava. Ao invés da extinção da noção de artista, ao mesmo tempo que a de obra, produziu-se uma exacerbação do estatuto moral e social do artista, uma supervalorização do ser artista"'.

16 No ponto de vista de Umberto Eco (1991), o conceito de abertura da obra de arte diz respeito tanto aos modos de colaboração do espectador, com os processos de liberdade interpretativa no discurso da obra, como na contribuição do espectador, na alteração de obras "em movimento", intercambiáveis, que se realizam 
ao de seus contemporâneos Dadaístas - percorreu, influenciou e se transformou ao longo de todo o século $\mathrm{XX}$, levando a emergência dessa nova postura ética ante os modos de produção artísticos vigentes, na qual: a criação artística é assumida como atividade, algo que ocorre entre a arte e a vida; o artista torna-se uma espécie de propositor; e o espectador passa a vivenciar as múltiplas experiências possíveis decorrentes dessas proposições, fazendo da obra um evento, um acontecimento. No bojo dessa posição, as produções que se seguiram à primeira metade do séc. XX concentraram-se menos na promoção de obras-resultado - carregadas de signos comportamentais condicionados à mera contemplação da obra pelo observador - e, mais, na realização de obras-processo - à espera da experimentação do espectador, em favor de uma maior plasticidade estética e cognitiva (ECO, 1991).

É fato que essa fortuna crítica teve múltiplos desdobramentos no percurso do seu processo histórico. No limite, conduziu à transvaloração da arte e à ressemantização do objeto a partir da problematização das categorias tradicionais da pintura e da escultura para, "recorrendo à linguagem verbal, pensar, em palavras, a relação entre plano de expressão e plano de conteúdo" (OLIVEIRA, 2002, p. 43). As décadas de 1960 e 1970, em especial, não só efetivaram a transformação balisar no campo da arte da forma em atitude (DUVE, 2003), como marcaram a efervescências dos movimentos ${ }^{17}$ que cortejaram esse engajamento, no qual a "obra se distancia do seu enquadramento, como objeto artístico de contemplação e consagração, orientado pela galeria modernista, para uma ampliação de campo de atuação" (GRANDO, 2009, p. 182). Exemplos da busca por essa outra dinâmica de princípios - cujos processos criativos se dão menos na preocupação com a fisicalidade do objeto e mais na imbricação das suas relações de fabricação e interação com o mundo exterior - é o caso de Robert Rauschenberg, Andy Warhol, Yves Klein, Grupo Fluxus, Allan Kaprow, Joseph Beuys, Vito Acconci, Robert Smithson, Daniel Buren, Donald Judd, Joseph Kosuth, e, obviamente, no contexto brasileiro, Hélio Oiticica e Lygia Clark, só para citarmos alguns.

Ora, não à toa o interesse desses, e de inúmeros outros artistas desse mesmo período, sobre a dimensão fenomenológica da arte - isto é, naquilo que DEWEY (2010), já na década de 1930, buscou formular através da concepção de arte como experiência. Nutriam-se tanto pelo desejo de exceder os processos de criação convencionais - explorando novas temporalidades, materialidades e meios - quanto pelo ímpeto em transbordar os limites estéticos impostos pelos espaços expositivos institucionalmente destinados à atividade e à fruição artística, a saber, os museus e as galerias. Essas frentes de ação artística - em sua multiplicidade de posições e de contextos - afastaram-se de um estatuto poético puramente formalista ${ }^{18}$, afirmando o modus

\footnotetext{
e se transformam a partir de trocas diretas com o participante. É importante frisar que essa abordagem vem na esteira das reflexões oriundas da teoria estética da recepção, proposta pelo teórico alemão Hans Robert Jauss (1994). Segundo essa teoria, os atos de leitura e recepção pressupõem interpretações distintas e atos criativos que convertem a figura do receptor em co-criador.

17 Segundo Ricardo N. Fabbrini (2012), esses movimentos remetem às manifestações artísticas do período denominado de vanguardas tardias - posteriores a Segunda Guerra Mundial - segundo o qual os artistas ainda se orientavam pela experimentação da forma artística que remontam as vanguardas heroicas da primeira metade do século XX, entretanto via radicalização de seus ideários.

18 A questão do formalismo teve na figura do crítico de arte norte-americano Clement Greenberg o seu principal porta-voz. O termo "formalismo" começa a ser utilizado, nos textos norte-americanos sobre arte,por volta dos anos de 1960. Embora num primeiro momento o termo carregasse, para o crítico, uma conotação extremamente vulgar, na década de 1970, ele passa a utilizá-lo sem essa acepção, ao apontar para uma certa ênfase que o termo estabelecia acerca do rigor
} 
operandi pautado na poética do processo (FREIRE, 1999), de caráter radicalmente ${ }^{19}$ político e crítico. Nesses termos, cumpri destacar, em especial, as contribuições das experimentações tensionadas pela minimal art e pela arte conceitual, no que concerne a interdependência entre processo e obra. $E$ isso porque, conforme pontua Michael Archer (2008, p. 77), enquanto o minimal art "tinha achado que o significado de um objeto de arte jazia, em certa medida, 'fora' dele, nas suas relações com o meio ambiente", a arte conceitual, por sua vez, "atraiu as tarefas da crítica e da análise para a esfera do fazer artístico".

Contudo, é indiscutível o quanto que no âmbito do contexto artístico brasileiro as proposições agenciadas por Hélio Oiticica e Lygia Clark intensificaram, nesse período, essa interdependência, implicando profundas remodelações no que tange os processos criativos e expressivos - cujos desdobramentos se fizeram presentes na arte dos decênios seguintes, e ainda hoje. Tanto no Hélio quanto em Lygia, a ênfase dos seus processos de criação perscrutavam a criação enquanto experiência intensificadara do real, assumindo a dimensão da relação entre arte e vida como vivência partilhada, em um apelo estético que convida à diluição dos contornos junto à potência de criação. Para ambos, interessa senão os modos com que diferentes sujeitos se relacionam num dado período de tempo, num dado espaço físico, uns com os outros e com a "obra" - colocando em destaque o que Oiticica denominou como além-participação ${ }^{20}$. Os processos criativos e expressivos são explorados, aí, como uma espécie de sistema aberto, ou seja, enquanto atividade que tanto implica "o artista - nas suas intenções e presença - como o contexto - naquilo que não pode ser controlado pelo artista e que não é neutro - como o espectador - na maioria dos casos entendido como figura ativa do processo" (CRUZEIRO, 2014, p. 122-123).

É importante frisar que por detrás dessa matriz de pensamento e ação sobre a linha tênue entre processo e obra - em que sentido e materialidade são construídos no processamento das relações estabelecidas na criação em ato - há, sem dúvida, toda uma tendência de produção em que tempo, corpo e espaço são tomados, simultaneamente, como problema estético e político da criação artística, ora incorporando-os, ora transformando-os por meio da obra (GALARD, 2007; RANCIÈRE, 2012; HUYSSEN, 2014). Trata-se, aí, não só de uma abordagem que colocou em destaque, entre outras questões, a necessidade de se preservar ${ }^{21}$ os recursos da criação, dando-lhes especial

artesanal que poderia ser detectada na arte modernista. Assim, o formalismo derivaria do aspecto rigoroso, "frio", do modernismo e constituiria uma das suas categorias essenciais, especialmente na pintura e na escultura. Segundo essa posição, qualidade da obra de arte residia exclusivamente nas suas relações formais: intervalos de cor e forma e o arranjo desses intervalos na composição do quadro e, portanto, tudo o que não pertence à esfera da forma pertence necessariamente à do conteúdo - âmbito frequentemente desprezado pela postura reacionária do crítico.

19 Se as vanguardas artísticas, a partir do final do século XIX, levaram ao extremo a necessidade de renovar o pensamento crítico, a arte das últimas décadas do século XX pôs novamente em xeque o discurso teórico sobre as vanguardas que vinha se consolidando. Nesse segundo momento, não só era necessário romper com os parâmetros instituídos a partir da arte já consagrada a fim de pensar uma arte nova, que não obedecia mais a esses parâmetros, mas essa quebra precisou ser radicalizada e passou a ter um duplo alcance, voltando-se tanto para a avaliação da prática artística quanto para o questionamento da própria história da arte, como discurso teórico explicativo.

20 A participação levou o artista ao além-participação. Nas palavras de Hélio Oiticica (1968), "creio que já superei o 'dar algo' para participar, estou além da 'obra aberta'; prefiro o conceito de Rogério Duarte, de projeto, no qual o objeto não existe como alvo participativo, mas o 'processo' e a 'possibilidade' infinita no processo, a 'proposição' individual em cada possibilidade".

21 É notória, por exemplo, a preocupação tanto do Hélio quanto de Lygia em guardar e organizar seus textos teóricos, poéticos, rascunhos, correspondências enviadas e recebidas, desenhos e instruções de suas proposições. Ao fazê-lo, ambos constituem um verdadeiro arquivo de suas poéticas, numa tentativa de sistematizar os caminhos para o conhecimento e a experiências de suas propostas, evidenciando que os processos de criação de uma obra não se esgotam na materialidade do objeto. 
atenção - posto que tempo, lugar e memória se transformam em aspectos constitutivos e testemunhas materiais da dinâmica criadora da "obra". Privilegiando-se, assim, "[...] uma estética não programática do artista" (KOSSOVITCH, 2005, p. 18) - que subsistiria, ainda que com outras formulações e conformações, no fazer artístico na condição histórica do presente - os eixos instaurados pela criação artística no último quarto do século XX conduziram, também, à reflexão da própria história da arte para além do seu anunciado fim (DANTO, 2000) e da própria crítica de arte para além da sua alegada morte (MCDONALD, 2007). Disso resulta o entendimento de que, dada a atitude de muitos artistas em agir sobre essa linha tênue que, até então, separava os processos expressivos dos criativos e receptivos, a compreensão e a discussão do trabalho de arte, naquilo que diria respeito à tarefa do historiador e do crítico não poderia mais ser a mesma, calcada no uso "[...] de métodos e procedimentos de leitura herdados da clareza autodefinida dos ismos modernistas" (COCCHIARALE, 2001, p. 337). É o que nos adverte, também, a filósofa francesa Anne Cauquelin (2005):

[...] trata-se de interpretar as novas regras do jogo, teorizando esse pluralismo sem lhe aplicar as normas do passado. As noções de originalidade, de conclusão, de evolução das formas ou de progressão na direção de uma expressão ideal não têm mais nenhuma prerrogativa nesse momento de atualidade pós-moderna (CAUQUELIN, 2005, p. 132).

\section{A crítica de arte no entrecruzamento da palavra com a imagem}

Sabe-se que os documentos e arquivos de criação sempre foram fontes para a crítica e para a história da arte (CIRILLO, 2019a), auxiliando, entre tantas outras frentes, na compreensão e elaboração dos estudos sobre a história das obras entregues ao público. Contudo, é na década de 1980, na esteira de um movimento mais amplo de resgate da memória e da conscientização da sociedade sobre a importância dos arquivos (SANTOS, 2005), que o trato dos documentos ganhou abrigo institucional, acelerando a consolidação dos estudos do processo de criação em outros campos das artes, além da filologia e crítica literária, ou da história das ciências. Segundo José Cirillo (2019a), o estudo dos registros residuais do processo de criação de artistas, no campo das artes visuais, tem gerado inestimáveis contribuições à teoria, crítica e história da arte, uma vez que ele abre "caminho para um mapeamento e contato com as decisões e incertezas do artista no seu processo de aproximação do objeto expressivo desejado, revela a obra a partir de seus procedimentos, diretrizes e encargos que envolveram o projeto em tela [...]" (CIRILLO, 2019a, p. 12).

Ainda a esse respeito, de acordo com Cecília Salles (2000, p. 03), "a análise dos documentos criativos dos artistas, longe de substituir a crítica de arte, tem o poder adensar o conhecimento relativo à obra", oferecendo ao âmbito da crítica das obras de arte um modo de aproximar-se delas, que ressalta a perspectiva eminentemente processual do seu movimento construtivo. Note-se, aí, que não se trata apenas do mero dar visibilidade a esses registros, ou mesmo de lhes atribuir o status de obra - 
tendência comum ${ }^{22}$ no trato desses documentos e arquivos em projetos curatoriais de inúmeras exposições no Brasil e no mundo - mas de olhá-los de modo investigativo, entendendo-os "dentro de uma rede de relações que ampliam nossa visão do próprio fazer artístico" (CIRILLO, 2019a, p. 15). Sob esse prisma, a crítica assumiria "[...] o vivo ativamento da potência das forças de criação" (ZIELINSKY, 2009, p. 96), uma vez que o estudo sobre a obra de arte, sustentado apenas na análise do objeto estático, parece "deixar de lado algo de determinante que está na obra e que, no entanto, não consegue nem ser tocado ou atingido" (SALLES, 2017a, p. 51). É o que procura destacar, também, Letícia Weiduschadt (2018):

[...] cada artista organiza seus arquivos de ideias, esboços, projetos e textos a sua maneira e esses vestígios das obras são um terreno fértil para a criação. Compreendemos que analisar esses arquivos e a sua fala pode ser um instrumento importante para compreender o modo como ele organiza o corpus de sua obra e a maneira como isso se relaciona com o mundo (WEIDUSCHADT, 2018, p. 166).

Em todo caso, é importante que se diga que lidar com os diferentes sistemas semióticos que compõem esses arquivos - como desenhos, escritos, anotações, colagens, rasuras, arquivos digitais - não implica a desvalorização do objeto em si, mas, sim, sua dessacralização como dito acabado, final, única forma possível (SALLES, 2006). O que esta ação evidencia é que a obra apresentada publicamente é apenas o resultado provisório de um conjunto de escolhas de um pensamento em construção, uma versão possível - ou um possível necessário, como definido pelo francês Louis Hay (2002) - dentro de um sem-fim de probabilidades do processo de criação. Indo além, operar no entrecruzamento desses registros com a obra entregue ao público significa "[...] compreender os modos de conexão das redes do pensamento em criação" (SALLES, 2006, p 11). Oferecer à crítica condições para que seja instaurada a discussão das obras como objetos móveis e inacabados, objetos em processo, em estado de transformação. Trata-se de uma abordagem que possibilitaria, inclusive, o reexame da atividade da crítica de arte - assentada na noção de juízo ${ }^{23}$ e quase sempre urdida de fora dos percursos de gestação das obras e das suas fontes - ao colocá-la em diálogo "com as indagações da ciência contemporânea, podendo adensar seus resultados ao estabelecer conexões com teorias que vão além da arte" (SALLES, 2000 , p. 07). Um claro exemplo disso seria a aproximação da crítica de arte com a crítica genética, dado que, como vimos, deve-se aos estudos genéticos a ênfase nos processos de criação e, portanto, o interesse pelos documentos e arquivos dos processos de construção da obra de arte. Para Cecília Salles (2000):

\footnotetext{
22 "O Museu Rodin, muitas vezes, oferece esse tipo de exposição que apresenta desenhos e moldes de uma obra específica. Para citar alguns outros exemplos, tivemos a exposição Paraíso, de Arthur Luiz Piza, no Instituto Moreira Salles (2005), onde foram expostos seus cadernos de anotações (os famosos moleskines). Segundo Piza (2005, p.8 e 4), ele nunca volta atrás, não tem julgamentos em relação a esses cadernos, 'não passam por processos de obras'. Essas 'confissões pessoais' ganham reproduções: as imagens foram escaneadas e emolduradas”( SALLES, 2006, p. 171).

23 Para Bernardo Barros Coelho de Oliveira (2009), a definição da palavra crítica ainda se encontra fortemente vinculada à consciência moderna da noção de juízo. Para ele, todos os verbetes relacionados ao radical grego kritiké insistem na ligação primeira com julgamento e escolha. Assim, no intento de buscar subsídios teóricos que desarticulem as noções de juízo e de crítica, o autor encontra na tese de Benjamin sobre Schlegel, um modo de compreensão epistemológica do crítico que, segundo ele, desde os românticos, se opõe à noção mais antiga de "juiz da arte". Nesses termos, de acordo com a tese de doutoramento de Walter Benjamim, "O conceito de crítica de arte no romantismo alemão", contrária a ideia de que "a crítica seria dependente do juízo, que recorta e distingue primeiro, e só depois oferece argumentos que justifiquem a escolha, [...] as obras de arte verdadeiras já são em si mesmas críticas e que o crítico digno deste nome desdobra e intensifica o que a elas é inerente, segundo critérios fornecidos pela própria obra" (OLIVEIRA, 2009, p. 26).
} 
A crítica genética abala, de certo modo, a concepção de estética tradicionalmente relacionada à obra entregue ao público - a obra de arte fechada na perfeição de sua formal final. As considerações de uma estética presa à noção de perfeição e acabamento defrontam-se com a obra em permanente revisão - balbuciante e inacabada. Esta crítica manuseia um objeto estético, ou melhor, um objeto que vai adquirindo caráter estético ao ser aceita por seu criador. Pode-se pensar, nessa perspectiva, numa estética em criação (SALLES, 2000, p. 2).

Perscrutá-la exige o estabelecimento de relações entre esses documentos e as obras. A crítica realizada no entrecruzamento desses registros com a obra entregue ao público tem como recurso metodológico básico o estabelecimento de relações. Analisá-los, os documentos de processo e o objeto, de modo isolados, sem relacioná-los, deixa "[...] de abrir frestas para o modo como o pensamento criativo se desenvolve e para maneiras como o conhecimento artístico é construído" (SALLES, 2006 , p. 109). À medida que esse contexto relacional vai sendo estabelecido, o crítico é confrontado com a variação de linguagens que compõem a "rede de ações bastante intrincada e densa que leva o artista à construção de suas obras" (Idem, ibidem, p. 121). Desse modo, desenhos, esboços, anotações, rasuras, revelam-se como índices da textura do percurso de natureza intersemiótica do pensamento em criação. Se a sua observância se torna uma aliada na compreensão dos mecanismos dessa estética em criação, é, contudo, imprescindível que os nexos oriundos da atenção crítica a esses índices estejam fundamentalmente em relação com a obra em construção. Pois só assim é possível pensar em como essas linguagens atuam no processo de criação, bem como "[...] examinar como maior acuidade aquilo que se tornou ficção ou os aspectos do processo que estão em proeminência" (Idem, ibidem, p. 182).

Observe que, se levado às últimas consequências, esse potencial gerativo de nexos complexifica ainda mais a já intrincada relação obra-processo. Isso porque, conforme destaca Cecília Salles (2006, p. 182), "muitas das questões que envolvem a criação artística nos transportam para além de seus bastidores, ou seja, além de seu passado registrado nos documentos das gavetas dos artistas". Sobretudo se tratam de obras que são processuais. Não por acaso, Cecília Salles estendeu sua reflexão teórica ao ponto de interseccionalizar as discussões no âmbito do pensamento da complexidade, dentro do qual podemos citar como um dos principais representantes o antropólogo, sociólogo e filósofo francês Edgar Morin. Essas interlocuções exigiram o desenvolvimento de maneiras de se aproximar do objeto artístico que dessem conta de uma perspectiva processual que se ocupa justamente dos fenômenos em sua mobilidade. Surge, assim, a crítica de processo, abordagem que adensa o argumento da criação como rede em construção. No que concerne à definição de criação como rede, Cecília Salles (2017a) o descreve da seguinte forma:

[...] um processo contínuo de interconexões, com tendências vagas, gerando nós de interação, cuja variabilidade obedece a princípios direcionadores. Esse processo contínuo, sem ponto inicial nem final, é um movimento falível, sustentado pela lógica da incerteza, englobando a entrada de ideias novas. As interconexões nos colocam no campo relacional: toda ação está relacionada a outras ações de igual relevância, sendo assim um percurso não linear e sem 
hierarquias. As interconexões geram os picos ou nós da rede, elementos de interação ligados entre si, que se manifestam como os eixos direcionadores de nossas pesquisas, ou seja, as recorrências encontradas nos documentos estudados (SALLES, 2017a, p. 49).

Com essa abordagem, a pesquisadora defende que os caminhos percorridos pelo artista no espaço e tempo da criação se constituem num ambiente de incertezas e imprecisões, cuja complexa e dinâmica rede de tendências ${ }^{24}$ que orientam o processo de construção dos objetos entregues ao público "podem ser observadas sob duas perspectivas: constituição de projetos poéticos ou princípios direcionadores e práticas comunicativas" (Idem, ibidem, p. 49). Nesse contexto de tendências vagas, escolhas de natureza diversas vão sendo feitas, levando à criação de uma obra possível, e não à obra de $a^{2} \mathrm{e}^{25}$ no sentido clássico. Ou seja, na medida em que se determinam certas restrições ou diálogos com os nós dessa rede, o artista constitui as linhas de força que, naquele momento, atribuirão contornos ao processo de criação relacionados à produção do objeto artístico. Em consonância com essa visada, as investigações ${ }^{26}$ que já há duas décadas pressupõem a criação como rede em construção, ocupam-se justamente da análise dos nós dessa trama de conexões móveis. Esses nós apontam para um nível de interação sistêmico ${ }^{27}$ (CIRILLO, 2019b) do processo de criação, cuja possibilidade de acompanhamento crítico das relações que vão sendo estabelecidas durante o percurso construtivo em ato, abrangem e ao mesmo tempo excedem o ato criador e a obra. No que tange essa postura crítica, atenta à urgência pela incorporação do movimento às discussões em torno das proposições artísticas no mundo contemporâneo, Cecília Almeida Salles \& Daniel Ribeiro Cardoso (2007) pontuam:

Algumas obras, incluindo todo o potencial que as mídias digitais oferecem, parecem exigir novas abordagens. Ao mesmo tempo, muitas dessas obras exigem novas metodologias de acompanhamento de seus processos construtivos e não somente a tradicional coleta de documentos, no momento posterior à apresentação da obra publicamente, isto é, a abertura das gavetas dos artistas para conhecer os registros das histórias das obras. Muitos críticos de processos passaram a conviver com o percurso construtivo em ato. Al-

24 Em relação às reflexões sobre as tendências dos processos do ponto de vista do projeto poético, podemos tratá-las a partir dos princípios direcionadores, de princípio ético e estético, relativos à singularidade do artista e que variam ao longo do tempo em função das circunstâncias espaciais e contingências temporais. Já do ponto de vista das práticas comunicativas, diz respeito à criação em sua contínua mediação com as redes culturais, a partir de uma grande variedade de diálogos inter e intrapessoais, como o caráter processual da obra, os receptores, a crítica e os membros dos grupos (SALLES, 2017a).

25 Segundo o filósofo italiano Giorgio Agamben (2013, p. 352), hoje, "a expressão obra de arte tornou-se opaca ou mesmo ininteligível. A sua obscuridade não diz respeito apenas ao termo arte, que dois séculos de reflexão estética tornaram problemático, mas também, e acima de tudo, ao termo obra. Até mesmo de um ponto de vista gramatical a expressão obra de arte, que usamos com tanta desenvoltura, não é nada fácil de entender. De fato, não está claro se, por exemplo, trata-se de um genitivo subjetivo, isto é, se a obra é feita da arte, pertence à arte, ou de um genitivo objetivo, no qual o importante é a obra e não a arte. Em outras palavras, se o elemento decisivo é a obra, a arte, ou a não bem definida mistura das duas. Além disso, (...) hoje a obra parece atravessar uma crise decisiva que a fez desaparecer do âmbito da produção artística, na qual a performance e a atividade criativa do artista tendem cada vez mais a tomar o lugar daquilo a que estávamos habituados a chamar obra de arte".

26 No campo das artes visuais, destaco, aqui, duas teses de doutoramento: a de Aparecido José Cirillo, intitulada "Imagem-lembrança: comunicação e memória no processo de criação", defendida em 2004, sob orientação da Profa. Dra . Cecília Almeida Salles; e a de Tailze Melo Ferreira, intitulada "Redes de escrituras: confluências narrativas nos diários de criação de 'A pedra do reino', microssérie de Luiz Fernando Carvalho", defendida em 2015, sob orientação da Profa . Dr. Leda Maria Martins.

27 "Considerando-se que os documentos de processo de artistas (rascunhos, cadernos de anotações, coleções, etc.) caracterizam-se como sistemas de memória exteriorizados, pode-se dizer que a interação dos sistemas verbais e visuais evidencia uma tendência comunicativa no processo de criação que, em tempos de redes, podemos pensar que ampliam-se para além dos diálogos do artista consigo mesmo, e apontam para um nível de interação sistêmico" (CIRILLO, 2019b, p. 129). 
gumas obras contemporâneas - mas não só - incitam, ou mesmo forçam, a constituição de novas metodologias para abordar seus processos de criação. Ao mesmo tempo, os resultados desses estudos mudam, de alguma maneira, os modos de abordá-las sob o ponto de vista crítico (CARDOSO \& SALLES, 2007, p. 46).

Note-se, portanto, que ao adicionar um olhar prospectivo ao retrospectivo da crítica genética, a crítica de processo não só renovou seu objeto de análise - a saber, os documentos de processo - como também engendrou a ativação da complexidade do próprio processo criativo, ampliando as possibilidades de discussão crítica sobre o emaranhado de ações físicas e intersubjetivas que envolvem os percursos da criação. Do mesmo modo, percebe-se o quanto que a teoria do processo de criação, decorrente desse olhar, vem tensionando ${ }^{28}$, ainda que pelas bordas das relações sistêmicas da arte, alguma interferência sobre os aportes teórico-metodológicos empregados no campo da crítica de arte. É bem verdade, também, que a própria arte de hoje, na complexidade e na dinamicidade de suas interações, estimula a aproximação do campo da criação artística com o da crítica, dado a inclinação desta em extravasar os bastidores e o objeto em si, passando a "integrar a malha dos objetos em criação" (SALLES, 2017a, p. 50).

\section{Conclusões em processo}

Por fim, embora a teorização de natureza geral dos processos de criação empreendida por Cecília Salles (1998) - ampliada, anos mais tarde, a partir da discussão da criação como rede em construção (SALLES, 2006) - não esteja exclusivamente assentada no campo das artes visuais, são inegáveis as contribuições deste campo no adensamento dessa teoria. Sobretudo por ter perscrutado a criação sob os signos da não linearidade, da mobilidade, da interação, da metamorfose e do inacabamento. O que denota que a teoria do processo de criação estaria, senão implicada, mínima e sensivelmente atenta as distensões do conceito de poiésis expostas pelas experimentações artísticas dos séculos XX e XXI - afinal, elas "impuseram novas metodologias para compreender seus processos construtivos e, ao mesmo tempo, reconceituaram tanto o processo de criação, como a própria obra" (SALLES, 2006, p. 184). Em todo caso, uma certeza podemos ter: ainda que a crítica da história da obra prescinda a dinamicidade da criação artística - especialmente ante obras que são processuais o mesmo não pode ser dito sobre a crítica de processo. Esta, desde sua emergência, tornou-se uma prolífica via de interlocução crítica com o processo criativo, em um sentido mais abrangente, e sobre o qual a crítica de arte tem todo o interesse em se nutrir. Nesse contexto, a crítica se impõe à necessidade de lidar permanentemente com os desafios teórico-crítico colocados pelo caráter, por natureza, processual e dinâmico, da criação que transborda o ato criador e a obra - não por acaso, uma entre tantas e difusas características da poética artística contemporânea (SALLES, 2006).

28 Ao enfatizarmos esse olhar, daríamos a ver "[...] uma outra possível abordagem para a arte, que caminha lado a lado com as críticas das obras, assim como foram entregues ao público. Trata-se, portanto, de um encontro bastante fértil com a crítica de obras" (CARDOSO \& SALLES, 2007, p. 45). 


\section{Referências bibliográficas}

AGAMBEN, G. Arqueologia da obra de arte. In: Revista Princípios, Natal, v. 20, n. 34, p. 349-361, jul.-dez. 2013. Disponível em: <https://periodicos.ufrn.br/principios/article/ view/7549>. Acesso em: 10 mai. 2019.

ARANTES, P. Arte e mídia no Brasil: perspectivas da estética digital. In: ARS, São Paulo, v. 3, n. 6, p. 52-65, 2005. Disponível em: <http://www2.eca.usp.br/cap/ars6/arantes. pdf>. Acesso em: 10 mai. 2019.

ARAÚJO. G. A. Poética(s): a criação artística em fricção com o(s) tempo(s) presente(s). In: Cena, Porto Alegre, n. 23, p. 111-120, set.-dez. 2017. Disponível em: <https://seer. ufrgs.br/cena/article/view/75024/44813>. Acesso em: 10 mai. 2019.

ARCHER, M. Arte contemporânea: uma história concisa. São Paulo: Martins Fontes, 2001. 320p.

BASBAUM, R. Cica e sede crítica. In: BASBAUM, R. (org.). Arte contemporânea brasileira: texturas, dicções, ficções, estratégias. Rio de Janeiro: Marca d'Água Livraria e Editora, 2001. 414p. p. 15-27.

BOURRIAUD, N. Formas de vida: a arte moderna e a invenção de si. São Paulo: Martins Fontes, 2011. 192p.

CAUQUELIN, A. Arte contemporânea: uma introdução. São Paulo: Martins Fontes, 2005. 176p.

CARDOSO, D. R.; SALLES, C. A. Crítica genética em expansão. In: Revista Ciência e Cultura, São Paulo, v. 59, n. 1, p. 44-47, jan.-mar. 2007. Disponível em: <http://cienciaecultura.bvs.br/scielo.php?script=sci_arttext\&pid=S0009-67252007000100019>. Acesso em: 10 mai. 2019.

CIRILLO, A. J. Imagem-lembrança: comunicação e memória no processo de criação. 2004. Tese (Doutorado em Comunicação e Semiótica) - Pontifícia Universidade Católica de São Paulo, São Paulo, 2004.

Arquivos pessoais de artistas: questões sobre o processo de criação. Vitória: UFES/ProEx, 2019a. 100p.

Além das nuvens brancas: mediações da cultura no processo de criação de Attílio Colnago. In: CIRILLO, A. J.; BELO, M.; GRANDO, A. (Org.). Nuvens no papel: impressões sobre o processo de criação. Vitória: UFES/ProEx, 2019b. p. 129135. $136 p$.

COCCHIARALE, F. Crítica: a palavra em crise. In: BASBAUM, R. (Org.). Arte contemporânea brasileira: texturas, dicções, ficções, estratégias. Rio de Janeiro: Marca d'Água Livraria e Editora, 2001. 414p. p. 377-381.

CRUZEIRO, C. P. Arte e realidade: aproximação, diluição e simbiose no século XX. Tese (Doutorado em Belas Artes) - Faculdade de Belas-Artes, Universidade de Lisboa, Lisboa, 2014.

DANTO, A. Arte sem paradigma. In: Arte \& Ensaios, Rio de Janeiro, ano 7, n. 7, p. 198- 
202, 2000.

DEWEY, J. Arte como experiência. São Paulo: Martins, 2010. 648p.

DUCHAMP, M. O ato criador. In: BATTCOCK, G. A nova arte. São Paulo: Perspectiva, 1975. 288p. p. 71-74.

DUVE, T. D. Quando a forma se transformou em atitude - e além. In Arte \& Ensaios (UFRJ). Rio de Janeiro, n. 10, p. 93-105, 2003.

ECO, U. Obra aberta. São Paulo: Perspectiva, 1991. 186p.

FABBRINI, R. N. O fim das vanguardas: da modernidade à pós-modernidade. In: IV Seminário Música, Ciência e Tecnologia: Fronteiras e Rupturas. São Paulo: Fapesp/ ECA - USP, 2012, p. 31-47.

FAVARETTO, C. F. Deslocamentos: entre a arte e a vida.In: ARS, São Paulo, v. 9, n. 18, p. 94-109, 2011. Disponível em: <http://www.revistas.usp.br/ars/article/ view/52788/56631>. Acesso em: 10 mai. 2019.

FREIRE, C. Poéticas do processo: arte conceitual no museu. São Paulo: Iluminuras \& MAC-USP, 1999. 200p.

FERREIRA, T. M. Redes de escrituras: confluências narrativas nos livros de processo de A Pedra do Reino, microssérie de Luiz Fernando Carvalho. 2015. 155 f. Tese (Doutorado em Estudos Literários) - Universidade Federal de Minas Gerais, Belo Horizonte, 2015.

GALARD, J. Ao lado da política: poderes e impoderes da arte. In PESSOA, F. \& CANTON, K. Sentidos e arte contemporânea - Seminários Internacionais Museu Vale do Rio Doce. Vila Velha: Museu Vale, 2007.

GOYA, E. J. Estudo de processo de criação artística. In: Simpósio Nacional de Pesquisa em Arte e Cultura Visual, 2., 2009, Goiânia. Anais do II Simpósio Nacional de Pesquisa em Arte e Cultura Visual. Goiânia: FAV/UFG, 2009. p. 01-12. Disponível em: <https://seminarioculturavisual.fav.ufg.br/up/778/o/2009.GT3a_Edna_Goya.pdf>. Acesso em: 10 mai. 2019.

GRANDO, Angela. Quebra de paradigmas e transitar etnográfico na arte brasileira na virada dos anos 60. In: XXIX Colóquio do Comitê Brasileiro de História da Arte. Vitória: UFES, 2009, p. 178-186. Disponível em: <http://www.cbha.art.br/pdfs/cbha_2009_ grando_angela_art.pdf>. Acesso em: 10 mai. 2019.

GRÉSILLON, A. Alguns pontos sobre a história da crítica genética. In: Estudos Avançados, São Paulo, v. 05, n. 11, p. 07-18, jan.-abr. 1991. Disponível em: <http://www. scielo.br/scielo.php?script=sci_arttext\&pid=S0103-40141991000100002>. Acesso em: 10 mai. 2019.

Elementos de crítica genética: ler os manuscritos modernos. Porto Alegre: UFRGS, 2007. 336p.

HAY, L. Essais de critique génétique. Paris: Flammarion, 1979. 236p. 
O texto não existe: reflexões sobre crítica genética. In: ZULAR, R. (Org.). Criação em processo: ensaios sobre a crítica genética. São Paulo: Iluminuras, 2002. p. 29-44. 253p.

HUYSSEN, A. Culturas do passado-presente: modernismos, artes visuais, políticas da memória. Rio de Janeiro: Contraponto, Museu de Arte do Rio (MAR), 2014.

KOSSOVITCH, L. Rancière e a Labor. In: Textura: Revista de Psicanálise, n. 5. São Paulo: Publicações Reuniões Psicanalíticas, 2005.

MCDONALD, R. The death of the critic. London/New York: Continuum, 2007.

OLIVEIRA, A. C. A interação na arte contemporânea. In: Galáxia (PUC-SP), São Paulo, n. 04, p. 33-66, 2002. Disponível em: <https://revistas.pucsp.br/galaxia/article/ view/1290/788>. Acesso em: 10 mai. 2019.

OITICICA, Hélio. A criação plástica em questão: respostas. In: Programa HO. Rio de Janeiro: Itaú Cultural, PHO 159/68, 1968.

OLIVEIRA, B. B. C. A construção do crítico: Benjamin e os românticos. In: ArteFilosofia, Ouro Preto, n.6, p. 26-33, abr. 2009. Disponível em: <https://www.periodicos.ufop. br/pp/index.php/raf/article/viewFile/692/648>. Acesso em: 10 mai. 2019.

RANCIĖRE, J. O espectador emancipado. São Paulo: Martins Fontes, 2012.

REGINA, S. L.; SANTOS, A. E. C. A crítica genética e os textos literários: um diálogo com outros saberes. In: Cadernos do CNLF, Rio de Janeiro, v. 19, n. 05, p. 09-22, 2015. Disponível em: <http://www.filologia.org.br/xix_cnlf/cnlf/05/001.pdf>. Acesso em: 10 mai. 2019.

RODRIGUES, U. A. Codicologia, história e cultura. In: ETD: Educação Temática Digital, Campinas, v. 18, n. 03, p. 614-627, jul.-set. 2016. Disponível em: <https://periodicos. sbu.unicamp.br/ojs/index.php/etd/article/view/8641656>. Acesso em: 10 mai. 2019.

SALLES, C. A. Criação em processo: Ignácio de Loyola Brandão e Não verás país nenhum. 1990. 255 f. Tese (Doutorado em Linguística) - Pontifícia Universidade Católica de São Paulo, São Paulo, 1990.

. Crítica Genética: uma introdução. São Paulo: Educ, 1992. 111p.

1998. $168 \mathrm{p}$

Gesto Inacabado: processo de criação artístico. São Paulo: FAPESP,

Imagens em construção. In: Olhar, São Carlos, ano 2, n. 4, p. 1-8, 2000. Disponível em: <http://www.ufscar.br/ revistaolhar/pdf/olhar4/Cecilia.pdf>. Acesso em: 08 out. 2019.

2006. 176p.

Redes da criação: construção da obra de arte. Vinhedo: Horizonte,

Crítica de processos criativos. In: 16 Encontro Nacional da Associação Nacional de Pesquisadores de Artes Plásticas (ANPAP) - Dinâmicas Epistemológicas 
em Artes Visuais, 16., 2007, Florianópolis. Anais do 16 Encontro Nacional da Associação Nacional de Pesquisadores de Artes Plásticas (ANPAP) - Dinâmicas Epistemológicas em Artes Visuais. Florianópolis: ANPAP/UFSC, 2007. p. 124-135. Disponível em: <http://anpap.org.br/anais/2007/2007/artigos/013.pdf>. Acesso em: 08 out. 2019.

Da crítica genética à crítica de processo: uma linha de pesquisa em expansão. In: SIGNUM: Estudos da Linguagem, Londrina, v. 20, n. 02, p. 41-52, ago. 2017a. Disponível em: <http://www.uel.br/revistas/uel/index.php/signum/article/ view/27384>. Acesso em: 10 mai. 2019.

Acompanhamento de processos de criação: algumas reflexões. In: Aspas, São Paulo, v. 7, n. 2, p. 27-39, 2017b. Disponível em: < http://www.revistas.usp.br/ aspas/article/view/139967/139691>. Acesso em: 08 out. 2019.

SANTOS, P. R. E. Arquivos de cientistas: gênese documental e procedimentos de organização. São Paulo: Associação de Arquivistas de São Paulo, 2005.

PINO, C. A. A ficção da escrita. São Paulo: Ateliê Editorial, 2004. 272p.

PLAZA, Julio. Arte e interatividade: autor-obra-recepção. In: ARS, São Paulo, v. 1, n. 02, p. 09-29, 2003. Disponível em: <http://www.mac.usp.br/mac/expos/2013/julio_ plaza/pdfs/arte_e_interatividade.pdf>. Acesso em: Acesso em: 10 mai. 2019.

TAVARES, M. Processos de criação na arte. [Palestra proferida em 23/09/2011]. In: I Seminário do Grupo Multidisciplinar de Estudo e Pesquisa em Arte e Educação. São Paulo: ECA, 2011. p. 36-48. Disponível em: <http://www3.eca.usp.br/sites/default/ files/form/biblioteca/acervo/producao-academica/002913390.pdf>. Acesso em: 10 mai. 2019.

WEIDUSCHADT, L. Quando devolvemos a voz ao artista. In: Arte em tempos de crise: olhares sobre o processo de criação - Seminário Íbero-americano Poéticas da Criação, 5., 2018, Vitória. Anais do V Seminário Íbero-americano Poéticas da Criação. Vitória: UFES/PROEX, 2018. p. 162-166.

WILLEMART, P. Crítica genética e história literária. In: Manuscrítica, São Paulo, v. 10, p. 165-185, 2001. Disponível em: <http://revistas.fflch.usp.br/manuscritica/article/ view/941>. Acesso em: 10 mai. 2019.

A crítica genética hoje. In: Alea: Estudos Neolatinos, Rio de Janeiro, v. 10, n. 1, p. 130-139, jan.-jun. 2008. Disponível em: <http://www.scielo.br/pdf/alea/ v10n1/v10n1a10.pdf>. Acesso em: 08 out. 2019.

ZIELINSKY, M. Crítica e criação em recíprocas conexões e rupturas. In: Porto Arte, Porto Alegre, v. 16, n. 27, p. 89-97, 2009. Disponível em: <https://seer.ufrgs.br/PortoArte/article/view/18190/10701>. Acesso em: 08 out. 2019.

ZULAR, R. (Org.). Criação em processo: ensaios sobre a crítica genética. São Paulo: Iluminuras, 2002. 253p. 